\title{
Out of Africa, for now
}

\author{
Mark Bernstein
}

Can J Neurol Sci. 2011; 38: 373-374

I stare out of the airplane window. I have done this many times before - flying into a large city in the developing world at night at the end of a long journey. This city looks a little darker, a little less well lit than other cities I have seen from the air. As with all the other times before, my heart beats out of control in my chest and my throat is parched. I am excited, nervous, bursting. I feel like a small boy on the first day at a new school. I walk off the plane trying to see and smell and hear and touch everything.

The daily car rides to and from the hospital and several long walkabouts reveal more about this town. The heat is brutal, the wet air mixes with my sweat and clings to my body and clothes leaving a grimy feeling. The air reminds me of many previous trips to Southeast Asia. It feels good though - even therapeutic. Any other weather would just not be right here. The roads are in poor condition - many are dusty paths with holes and ridges big enough to damage a car. Countless vehicles try to navigate the crowded streets. Horns beep but not in an angry way. Numerous small kiosks selling "street meat" and everything else line the narrow arteries. Young women gracefully balance massive baskets full of heavy loads of cut watermelon or bags of water and every other imaginable sellable item. Young men run

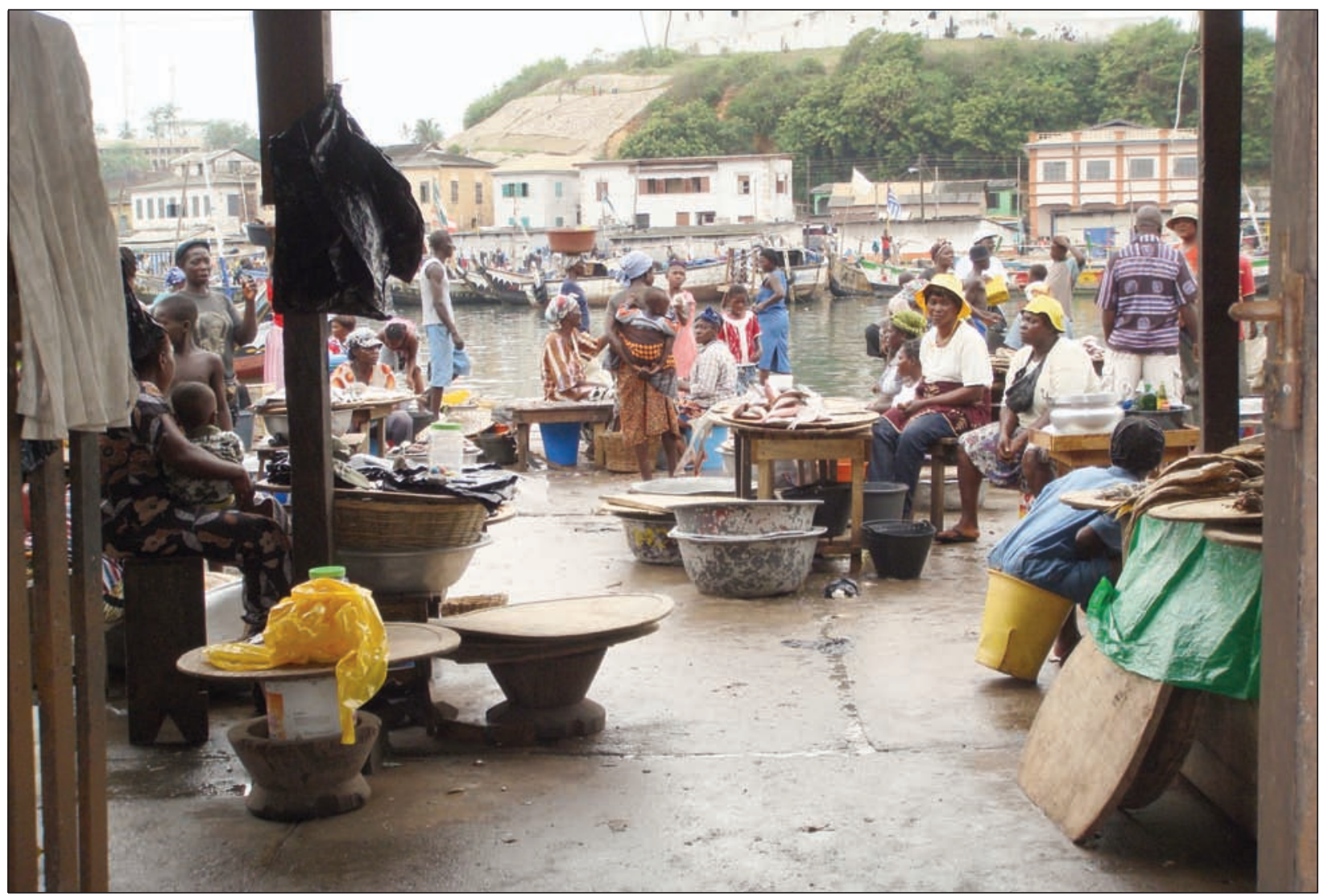

Figure 1: Fishmarket in Cape Coast, Ghana. 


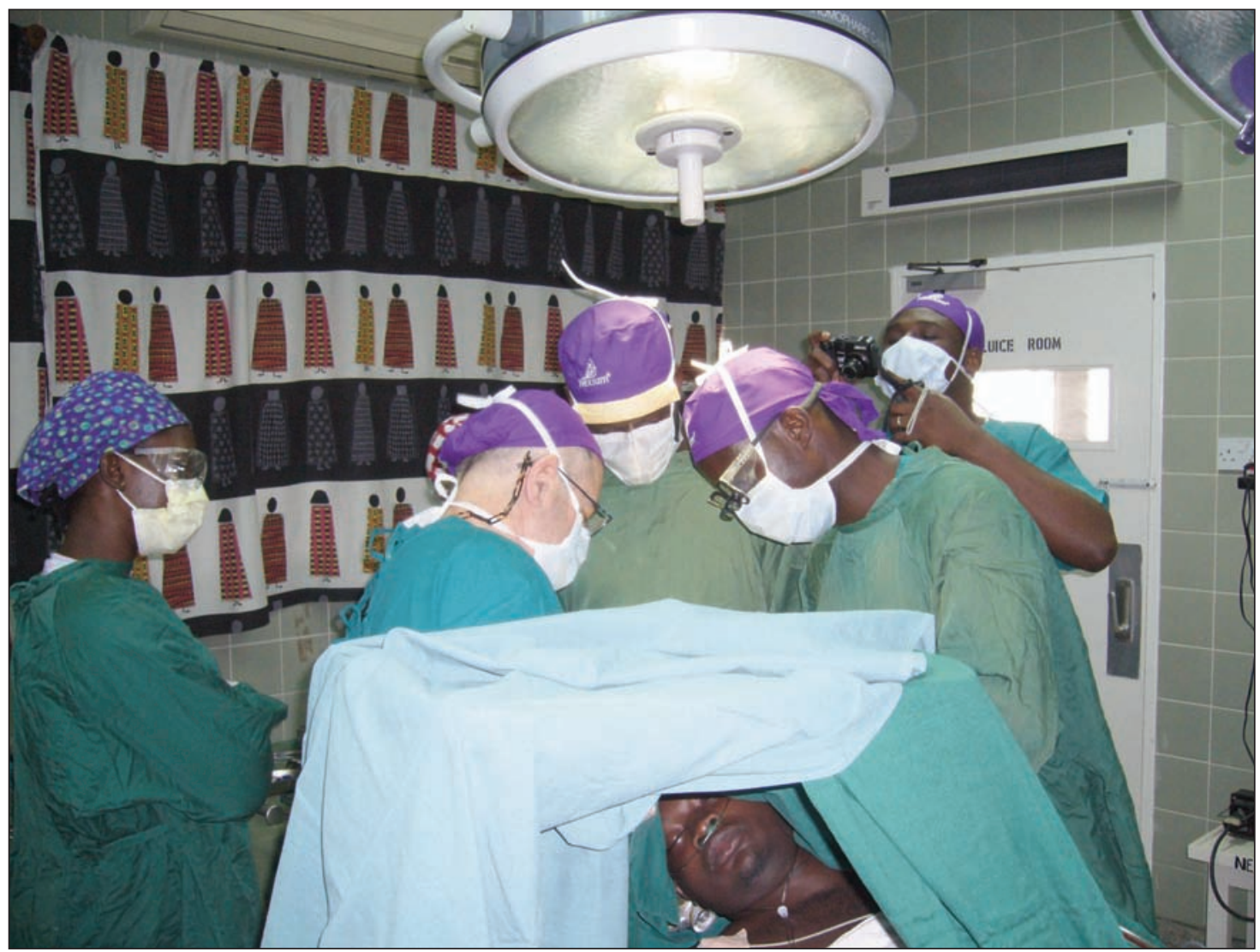

Figure 2: Teaching awake brain tumour surgery to local surgeons at Korle Bu Teaching Hospital, Accra, Ghana.

between the slowly moving cars in the traffic trying to peddle their wares to passengers. People are very beautiful with big white smiles. They usually grin shyly when we make eye contact. They are poor but seem genuine, happy, and sweet. They talk openly if we engage them.

Its Accra, the capital of Ghana, in the late spring. I have brought a team of surgeons and nurses to help teach what we can to this developing neurosurgery unit. During the two weeks we are moved by the big hearts, deft hands, and nimble brains of the Ghanaian neurosurgeons and the compassion and good nature of the nurses. They lack resources but are doing a good job. We learn as well as teach. The chemistry that developes between the African and Canadian teams is a thing of beauty.

During our stay we visit one of the castles on the coast where slaves were held hundreds of years ago. A time when people were stolen from their families inland, walked for months tied by the neck to the coast, held in deplorable dungeons, pushed through the door of no return to spend months in the filthy hot overcrowded holds of ships bound for distant strange lands. And then they served their owners, not knowing the fates of their family members and with little chance of ever seeing them again. I step into the door of no return but cannot feel what they must have felt. But this is the place where all that terribleness started.

The two weeks are a magic experience. The exit from Ghana is complicated by poor Mother Nature's latest hiccup - the volcanic dust cloud over Europe. So the KLM flight through
Amsterdam scheduled for the night after the eruption is luckily turned into the Accra to New York direct flight. The African magic continues.

On the plane I settle into my seat thankful to be homeward bound but in my head are swimming different and conflicting emotions. I start to watch a touching and poignant movie and soon I find myself quietly weeping. I dab my tears so the woman sitting beside me, going home to Nashville after a visit with family in her native Ghana, will not think I'm nuts. But it soon dawns on me that I am not weeping over the movie. I weep for the beauty and magic I have been a part of. I weep because of the elegant and touching way the local and visiting teams interacted and embraced each other. I weep because of the wonderful people I have met so far from home - the dedicated nurses and surgeons. These are people I feel I have known all my life, new brothers and sisters, or maybe sons and daughters. I weep for all the beauty that exists, and for all the sadness that remains beside it. But I really weep because I have fallen in love with Ghana. For the time being it will have to be a long-distance relationship but I am trying to learn patience and I will wait.

Late at night above Toronto two weeks later the city looks much brighter from the air than Accra did. On the ground the streets are wide and clean, with no road side kiosks. Its safe and comfortable and good and its home but it doesn't feel as alive as the faraway place did. I think of Accra and I smile. 